\title{
Entrevista
}

\section{ENTREVISTA COM BERNARD LAHIRE}

\author{
Realizada por Guilherme Seto Monteiro e Mariana Toledo Ferreira*
}

Bernard Lahire, sociólogo, nasceu em Lyon, na França, em 1963. Atualmente, é professor de sociologia da École Normale Supérieure Lettres et Sciences Humaines, em Lyon, e diretor da equipe Dispositions, Pouvoirs, Cultures, Socialisations, do Centre Max Weber (CNRS). Realizou sua formação na Université Lumière Lyon 2, onde apresentou seu doutorado em 1993, sob orientação do professor Yves Grafmeyer.

De 13 de novembro a 17 de dezembro de 2011, o professor Lahire ocupou a "Cátedra Lévi-Strauss", em uma iniciativa institucional conjunta da Universidade de São Paulo e do Consulado Geral da França em São Paulo. Na ocasião, foi acolhido pelo Programa de Pós-Graduação em Sociologia da Faculdade de Filosofia, Letras e Ciências Humanas da Universidade de São Paulo, onde ministrou a disciplina Problemas e Métodos da Sociologia das Disposições.

Como membros da Revista Plural e alunos do curso ministrado pelo professor Lahire, decidimos convidá-lo para uma entrevista, cujo objetivo principal seria tocar, de maneira resumida, nas questões mais importantes abordadas na ocasião, como forma de compartilhar o conteúdo da disciplina para alunos de outros programas de pós-graduação e demais interessados. O convite foi aceito sem hesitação. Esperamos que esta entrevista encontre um público interessado em conhecer as ideias desse importante pesquisador em sociologia da educação e da cultura.

Revista Plural Gostaríamos de começar a entrevista perguntando sobre sua formação acadêmica e trajetória profissional. Onde o senhor estudou? Qual foi seu ponto de partida? Quais são suas principais atividades e sua posição atual no meio universitário francês?

Recebido para publicação em 14/05/2012.

Aceito para publicação em 12/11/2012.

* Mestrandos do Programa de Pós-Graduação em Sociologia da Universidade de São Paulo (PPGS/ USP) e membros da Comissão Editorial da Revista Plural. 
Bernard Lahire Meu percurso de formação sociológica começou em 1981-1982, na Université Lumière Lyon 2, e terminou formalmente em março de 1990, com a defesa de minha tese de doutorado nessa mesma universidade (Formes sociales scripturales et formes sociales orales: une analyse sociologique de l'«échec scolaire» à l'école primaire, 1016 p.). Eu terminei o liceu [colegial], onde realizava estudos científicos e técnicos, para entrar em uma faculdade de sociologia. Foi para mim uma ruptura, pois inicialmente tinha optado por estudos que me levavam em direção à profissão de engenheiro, mas me dei conta, através da experiência no liceu, que esse mundo não me interessava. Tanto a cultura matemática, muito formal, quanto a cultura tecnológica, muito funcional, não respondiam à minha necessidade de dar algum sentido ao mundo social. Proveniente de um meio operário e me afastando progressivamente dele pela via escolar, eu tinha numerosas questões sobre o funcionamento da sociedade, sobre o lugar que eu ocupava, sobre as razões de meu sucesso escolar, considerando que ninguém em minha família havia obtido nem o baccalauréat, etc.

A escolha pela sociologia foi uma maneira de dar conta dessas interrogações, evitando a introspecção (eu tinha resistência a certa forma de psicologia) e privilegiando a observação e a análise objetiva da realidade social.

Apaixonado por esses estudos, eu continuei os anos e os diplomas com prazer. Durante esse percurso, fiz também cursos em outras disciplinas: notadamente em linguística e demografia histórica. Depois de terminar minha tese de doutorado, tornei-me assistente temporário de ensino e pesquisa na mesma universidade; em seguida, tornei-me mestre de conferências (1992) e, após obter uma habilitação para dirigir pesquisas em 1993 (Inégalités, partages, spécificités et différences dans les usages sociaux de l'écrit. De l'école élémentaire aux pratiques en milieux populaires), tornei-me, enfim, professor universitário (em 1994).

Em seguida, tive a chance de ser nomeado para o Institut Universitaire de France (de 1995 a 2000), sendo liberado da função de ensino para poder conduzir pesquisas livremente. Depois, a partir de 2000, tornei-me professor da École Normale Supérieure. Dirigi, entre 2003 e 2010, um laboratório de pesquisa, o Groupe de Recherche sur la Socialisation. Logo em seguida, devido a remanejamentos institucionais impostos pelo Ministério da Pesquisa francês, constituí, a partir de 2011, uma equipe de pesquisa, Dispositions, Pouvoirs, Cultures, Socialisations, no interior de um grande centro de pesquisa (Centre Max Weber).

No entanto, a meu ver, tal percurso institucional não tem grande sentido; ele esconde o essencial, ou seja, as atividades de pesquisa e as publicações que fo- 
ram numerosas e muito estimulantes para mim. É preciso, então, fazer referência a uma atividade editorial muito excitante: eu coordeno, desde 2002, uma coleção de obras em ciências sociais (Laboratoire des sciences sociales), de uma grande editora parisiense (Éditions la Découverte), onde pude, por exemplo, traduzir os textos do antropólogo Jack Goody, de historiadores como Benedict Anderson ou Lawrence Levine e ainda um texto mundialmente inédito de Norbert Elias sobre Freud.

Revista Plural Em seus trabalhos, podemos perceber uma tentativa de colocar em questão o conceito de habitus, tal como utilizado por Pierre Bourdieu. Você poderia nos dizer brevemente por que não considera o conceito suficiente para a compreensão da incorporação do social nos indivíduos? De que maneira o conceito de disposições pode ser considerado uma alternativa interessante?

Bernard Lahire A crítica que formulei, no que diz respeito à teoria do habitus, está ligada às dificuldades que encontrei no decorrer de minha pesquisa. Para resumir um processo lento, com críticas sendo formuladas ao longo das pesquisas, concluí que é o conjunto dos termos da definição de habitus que deve ser revisado. O habitus como "sistema de disposições gerais e transponíveis" não permite levar em consideração toda a variação do que denomino "patrimônios individuais de disposições e competências". A noção de "sistema", assim como a definição do habitus como "a fórmula geradora das práticas", é muito homogeneizante: os atores são portadores de disposições extremamente variadas, de natureza diversa, geralmente muito heterogêneas e, às vezes, contraditórias. Bourdieu apresenta uma realidade "disposicional" de maneira muito coerente, o que não acontece necessariamente, nem sistematicamente. Em seguida, essas disposições não são mobilizadas em seu conjunto, em todas as práticas dos indivíduos; elas podem ser fracas (quando o tempo de socialização ou de constituição for relativamente curto) ou fortes (quando o tempo de socialização ou de constituição for bastante longo). Ainda, essas disposições não são necessariamente gerais e transponíveis (o que pressupõe Bourdieu em sua definição): é possível observar disposições que são ativadas ou desativadas em função das restrições próprias de cada contexto.

Eu retomo, portanto, o conceito de disposição, que é central em minha sociologia, mas modificando grande parte daquilo que Pierre Bourdieu, a partir de bases exclusivamente teóricas, pressupôs e postulou. O conceito de habitus, no sentido preciso dado por Bourdieu, não é mais que um caso possível dentro do conjunto de "patrimônios individuais de disposições”. Ele é o caso mais provável 
nas sociedades tradicionais, com forte coerência socializadora (não é por acaso que Bourdieu mobilizou essa noção para discutir uma sociedade como a sociedade Kabila), mas menos provável nas sociedades complexas, estendidas e fortemente diferenciadas.

Revista Plural Por que falar de "disposições" no plural? O que seria um "ator plural”?

Bernard Lahire Acho que seria especialmente importante se perguntar quais são as condições sócio-históricas em que um ator pode ser portador de disposições plurais ou não. Para que um ator seja portador de um patrimônio de disposições muito coerente e homogêneo, ele precisa ter sido socializado em condições muito homogêneas. O modelo "ideal” de situação que produziria algo como um habitus é o modelo de "instituição total" (no sentido de Goffman), uma criança nascida em uma instituição total e que nunca dela saiu. Aí estão as condições para se produzir coerência "disposicional". Mas o que observamos em sociedades industrializadas, escolarizadas e altamente diferenciadas? Ora, desde a infância, são fortes as concorrências socializadoras entre a família, a escola, os grupos de pares e o conjunto de instituições ou de atores que contribuem para socializar na infância (babás, creches, pediatras, psicólogos, etc.). E, então, os atores em nossas sociedades estão inscritos em quadros de ação que são em parte heterogêneos: seus patrimônios de disposição são moldados à imagem dessa pluralidade.

Revista Plural Em A cultura dos indivíduos, você mostra, fazendo uma releitura dos dados de A distinção, de Bourdieu, que, a partir dos dados com os quais ele demonstrou a existência de habitus de classe bastante homogêneos, é possível mostrar a presença de variações. Essa diferença se explica por uma questão de escala de análise ou de olhar sociológico? Por outro lado, é possível aproximar a frequência de perfis culturais dissonantes a certa dissolução das fronteiras da legitimidade cultural?

Bernard Lahire As variações interindividuais (de um indivíduo a outro, no seio do mesmo grupo ou classe) ou intraindividuais (de um domínio a outro da prática, em um mesmo indivíduo) de práticas e preferências culturais só podem ser observadas, evidentemente, se nos damos os meios para vê-las. Durante muito tempo, os sociólogos se interessavam apenas pelas diferenças entre as classes, porque eles eram incapazes de dar sentido às variações interindividuais ou intraindividuais. Essas variações continuaram invisíveis porque eram ininterpretáveis. Como os pesquisadores ignoravam sistematicamente essas variações, 
devido aos métodos estatísticos utilizados, tudo se passava como se elas não existissem. Foi preciso que a sociologia progredisse teoricamente para integrar essas questões, quer dizer, para aceitar a explicação das complexidades individuais. Por muito tempo, o medo de "recair na psicologia" inibia os pesquisadores.

Mas essas questões são também impostas ao olhar contemporâneo (elas são agora mais difíceis de ignorar), devido à modificação da oferta cultural e do fato de que os limites da "cultura legítima” foram borrados. Isso se explica pela entrada no domínio da cultura legítima de numerosas artes ou gêneros que eram antes considerados "indignos" (ojazz, a história em quadrinhos, o romance policial, a fotografia, o cinema, entre outros), pela redefinição da cultura legítima, no sentido de uma integração da ciência (considerada, durante muito tempo, como estando fora do domínio da cultura) e pela transformação da relação de força entre as culturas eruditas e as de entretenimento. Todos esses fenômenos contribuíram para multiplicar as dissonâncias culturais.

Revista Plural No centro de sua obra, há uma proposição de se fazer uma sociologia em outra escala. Você poderia nos explicar em que consiste tal proposição e no que consiste essa mudança de escala? O que é uma sociologia em escala individual? Ademais, de que maneira tal ideia tem relação com sua proposta de fazer uma "sociologia psicológica"?

Bernard Lahire Eu dizia anteriormente que a questão das variações interindividuais e intraindividuais dos comportamentos esteve por muito tempo fora do campo de investigação dos sociólogos. Eram significativas para os sociólogos as variações intersocietais e, sobretudo, intergrupo (ou classe), no seio de uma sociedade, mas nos demos conta de que era frequentemente necessário compreender os indivíduos em sua singularidade relativa, continuando, é claro, no interior da reflexão e da explicação sociológica: compreender os casos atípicos ou improváveis estatisticamente (o que eu fiz para o caso das crianças oriundas de ambientes populares, em situação de sucesso escolar) ou compreender casos singulares, porque são objetivamente diferenciados, por suas práticas, como é o caso dos criadores (por exemplo, compreender Mozart a partir de Elias; Flaubert a partir de Bourdieu; ou Kafka por mim). Para compreender os indivíduos em sua singularidade relativa é necessário se aproximar deles e parar de considerá-los unicamente como "representantes de grupos ou de categorias". É preciso reconstruir os elementos de um percurso individual e compreender o tecido social desse indivíduo singular.

Eu fui levado, nesse sentido, a falar de "sociologia psicológica", sobretudo para evocar essa mudança de escala de observação e de análise, mas a expres- 
são provocou mal-entendidos. Alguns consideraram, por exemplo, que eu queria desenvolver uma espécie de "psicologia social” e começaram a perguntar minha opinião a respeito de trabalhos de psicologia. Portanto, eu passei a falar em "sociologia em escala individual”, em sociologia de variações interindividuais e intraindividuais dos comportamentos. É mais técnico e mais preciso e não alude à ideia de uma união com a psicologia.

Revista Plural Então, como podemos fazer a articulação entre o indivíduo e a classe, em uma sociologia em escala individual? As classes desaparecem?

Bernard Lahire Obrigado por essa questão! Ela me permite esclarecer um ponto muito importante deste debate. Se pensarmos em termos de escala de observação, não podemos produzir nenhum mal-entendido sobre tais questões. É possível dizer que aqueles que trabalham sobre micróbios, com a ajuda de microscópios, fazem os planetas desaparecerem? A resposta é clara: evidentemente que não! No entanto, os sociólogos fazem esse tipo de questão e desconfiam daqueles que trabalham em uma escala que nega a existência de realidades passíveis de serem observadas em outras escalas. Como articular o indivíduo singular e a classe à qual podemos vinculá-lo? Tudo depende da questão que nos colocamos e do problema que queremos resolver. Se meu objetivo é compreender as diferenças entre classes, eu vou necessariamente homogeneizar as classes os as frações de classe. É uma operação necessária para poder comparar as classes. Mas todo mundo sabe que existe heterogeneidade no interior da classe (um cirurgião não é um advogado, mas também não é um dentista ou um clínico geral, etc.). Às vezes, eu preciso compreender os efeitos de uma série de propriedades sociais gerais combinadas em um único indivíduo (um cirurgião, homem, que é originário de determinado meio social, que teve determinados percurso escolar, formação religiosa, experiência profissional, familiar, cultural, etc.).

\section{Revista Plural Está presente também em seu trabalho uma problematização do} conceito de campo, difundido pelas pesquisas de Bourdieu. Quais são as lacunas e as imprecisões que você encontrou nesse conceito e em sua aplicação na análise de Bourdieu e seus discípulos?

Bernard Lahire Considero que o conceito de campo pode ser muito útil aos pesquisadores, se ele não for considerado uma "senha" universal. Para alguns pesquisadores, até mesmo Bourdieu, em alguns textos, o conceito de campo aparece como sendo o "bom contexto", no qual é sistematicamente necessário situar os atores para compreender suas práticas. Quando dizemos, por exemplo, que as práticas 
dos atores (quaisquer que sejam esses atores e essas práticas) devem ser compreendidas a partir do cruzamento entre habitus e um campo, está implícito que todo contexto de ação é necessariamente um campo. No entanto, esse conceito tem limites sócio-históricos de utilização e pertinência: existem sociedades sem campo (as sociedades tradicionais estudadas por antropólogos são sociedades sem Estado, sem escrita e sem campo) e, ainda, em sociedades onde existem campos, nem todo espaço social se organiza necessariamente sob a forma de um campo. Os campos correspondem a espaços de lutas pelo poder e se situam essencialmente no espaço das classes dominantes. Existem, então, numerosos espaços da sociedade que não podem ser compreendidos a partir desse conceito.

Além disso, para complicar mais a questão, a noção de campo emprega certo ponto de vista do conhecimento e negligencia outros. Por exemplo, a noção de "mundo" (Becker e Strauss), noção falsamente considerada prima da de campo, na verdade, não se interessa pelos mesmos tipos de atores nem pelo mesmo tipo de relações entre eles. Acredito, então, que é possível dizer, sem risco, que toda prática deve ser compreendida a partir do cruzamento entre disposições incorporadas (do passado incorporado) dos atores e contextos de ação. Mas esses contextos não são necessariamente campos, podem ser o espaço de relações de classe, um mundo, uma instituição, um microgrupo, um quadro de interação, etc. Nós não vamos tentar recortar (ou reconstruir) o mesmo contexto segundo o problema que estamos tentando resolver e as práticas que nos esforçamos a compreender.

Revista Plural No curso, também foi promovida uma discussão sobre os limites históricos, geográficos e contextuais de aplicação do conceito de "campo", uma espécie de crítica ao uso acrítico do conceito. Em uma ocasião, você propôs a utilização do conceito de "jogo" como uma alternativa possível nos contextos de difícil apreensão pela metodologia dos campos. Você poderia nos explicar brevemente as características do conceito, seus objetos e contextos de aplicação?

Bernard Lahire Já comecei a fornecer uma resposta à pergunta, mas vou dar sequência em relação à questão do jogo. Do mesmo modo que se deve ser prudente em relação aos limites históricos do campo e perguntar-se, por exemplo, sobre o que era a literatura antes da constituição de um campo literário no sentido empregado por Bourdieu (ele situava essa constituição ao fim do século XIX no que concerne à França), deve-se interrogar se todos os campos possuem as mesmas propriedades. Nesse ponto, parece-me que Bourdieu generalizou prematuramente as propriedades do campo, tendo por base seus primeiros trabalhos. Propus traçar, a partir disso, uma diferença entre os campos segundo os que possuem agen- 
tes permanentes ou não. Há, com efeito, uma grande diferença entre um campo acadêmico como o campo filosófico, no qual o conjunto de agentes é pago para filosofar e são, portanto, profissionais assalariados da filosofia, e um campo artístico como o campo literário, que é um espaço no qual os atores não se inscrevem senão "secundariamente", pois são constrangidos a ter uma atividade remunerada situada no exterior do campo literário. Então, propus chamar o espaço literário de jogo, para designar um "campo secundário" no seio do qual os atores habitualmente não são permanentes. O “jogo" - tido como mais ou menos fútil, secundário (enquanto adulto, só jogamos legitimamente se tivermos trabalhado) - opõe-se ao "trabalho" - tido como sério, principal. Muitos espaços artísticos são jogos, assim como certos espaços esportivos amadores (ainda restam alguns...).

Revista Plural Se considerarmos que o indivíduo frequenta múltiplos espaços e instituições e que ele é exposto a múltiplas influências ao longo de sua vida, como podemos identificar os contextos pertinentes para explicar uma prática determinada? No caso de Kafka, por exemplo, como podemos identificar os contextos mais pertinentes para compreender sua literatura?

Bernard Lahire Colocando a questão dessa maneira, vocês já estão em um bom caminho para fornecer uma resposta pertinente. O risco da teoria dos campos é aquele do reducionismo. Com efeito, uma parcela dos trabalhos sobre o campo literário ou sobre o campo filosófico busca, unicamente, nos limites do campo, as razões de tal ou tal obra no interior do campo, mas não se compreende completamente o que escreveu Kafka, se faz de sua obra uma espécie de resposta objetiva a outras obras concorrentes. Bourdieu, por vezes, pronuncia-se como se o campo literário tivesse a capacidade de autogerar as obras segundo a lógica específica ao campo e de modo totalmente autônomo. É uma ideia a um só tempo estruturalista e organicista, que coloca enormes problemas. Uma obra literária não é uma simples resposta a outras obras literárias. Cada obra literária é uma maneira, especificamente literária, de traduzir questões existenciais ligadas a um percurso biográfico e a uma época dada. A lista dos contextos pertinentes para compreender uma prática dada (literária, por exemplo) jamais está fixa de uma vez por todas. Ninguém pensa espontaneamente que é fundamental, para compreender os temas e o estilo de suas obras, reconstruir o contexto de formação escolar de Kafka como estudante de Direito na universidade e seu contexto profissional ordinário em uma companhia de seguros contra acidentes de trabalho.

Foi isso que tentei mostrar em meu trabalho sobre o escritor (Franz Kafka. Éléments pour une théorie de la création littéraire). O estilo bastante ascético de 
Kafka não está desvinculado da escritura seca e precisa do Direito, e suas metáforas judiciárias incessantes ( $O$ processo, $O$ veredicto, etc.) não são produto do acaso; as numerosas cenas de seus romances e novelas não estão dissociadas da observação que ele pôde fazer das cenas operárias nas empresas que ele foi encarregado de visitar, etc. De maneira mais evidente, pois Kafka mesmo deixou os traços para nos ajudar a compreender (com sua célebre carta endereçada a seu pai), sua obra só é compreensível ao se desvendar o enodamento no seio da configuração familiar entre o pai, a mãe e os filhos, isto é, as relações de poder e de autoridade no seio da família estão na origem de uma grande parcela das obsessões literárias de Kafka.

Revista Plural O que significa fazer uma sociologia, ao mesmo tempo, "disposicionalista" e contextualista? Em que consiste uma teoria da ação que leva em conta os contextos e as disposições? E, a partir dessa articulação, como podemos investigar as práticas sociais?

Bernard Lahire Vasta questão! Vou tentar esboçar um começo de resposta. Os diferentes tipos de teorias sociológicas têm tendência de operar uma redução, seja “disposicionalista”, seja contextualista - e assim me parece que cada uma detém uma parcela da explicação correta. A redução mais frequente é a redução contextualista. Os sociólogos vão dizer, então: "Diga-me em que contexto os atores estão, e eu lhe direi o que eles fazem, pensam, sentem, etc.”. Segundo os sociólogos, o contexto em questão será uma instituição, uma organização, um sistema de ação, um quadro local de interação, um campo, um mundo, uma classe, um grupo, etc., mas todos eles negligenciarão o passado incorporado dos atores (que neles se constitui de modo mais ou menos durável sob a forma de disposições e competências mentais e comportamentais). Inversamente, podem existir reducionismos “disposicionalistas". É mais raro, mas acontece. Nesse caso, os pesquisadores vão explicar os comportamentos ou práticas somente pelas propriedades incorporadas dos atores, apreendidas de maneira mais ou menos sutil: sua mentalidade, sua cultura, seus ethos, seu habitus, etc.; e essas propriedades explicam o que eles fazem, pensam e sentem em todos os contextos de suas práticas. E, então, negligenciam-se as constrições que fazem pesar cada contexto específico dado sobre os atores em questão. Parece-me, portanto, que os pesquisadores devem levar em conta, a um só tempo, as disposições (o passado incorporado, que não é senão o produto interiorizado da frequência, em contextos de ação passados) e os contextos presentes de ação. Em todo o caso, eu defendo que tal equilíbrio explicativo seja respeitado. 
Revista Plural Depois de tudo isso que discutimos, o que resta de Pierre Bourdieu? Você considera seu trabalho uma continuação ou uma negação crítica da teoria bourdieusiana?

Bernard Lahire Citei, em A cultura dos indivíduos, uma frase contida no livro A formação do espírito científico, do epistemólogo francês Gaston Bachelard, que resume perfeitamente minha posição: "Na obra da ciência, somente se pode amar o que se destrói, pode-se continuar o passado ao negá-lo, pode-se venerar seu mestre ao contradizê-lo". Logo, meu trabalho é, ao mesmo tempo, uma continuação e uma ruptura, um prolongamento de certas contribuições e uma crítica ao conjunto do que Bourdieu nos deixou de herança. Editei recentemente uma obra inédita de Norbert Elias sobre o conceito de sociedade em Freud e me dei conta de que tenho com Bourdieu a mesma relação que Elias tinha com Freud. Com efeito, Norbert Elias pode, sem dúvida, ser considerado como o mais freudiano dos sociólogos, sem jamais, todavia, ser assimilado como um epígono ou um continuador zeloso. Ele consegue essa rara performance científica, que consiste em construir uma obra, a um só tempo, totalmente dependente daquela do inventor da psicanálise e perfeitamente distinta e mesmo original. Ninguém duvida de que Elias se identificava com seu ilustre predecessor. Ele admirava em particular sua capacidade de renovar profundamente o conhecimento, em contracorrente às autoridades estabelecidas. No entanto, isso não o paralisa, quando se propõe a submeter o modelo freudiano ao exame crítico. Norbert Elias interroga exaustivamente cada elemento do modelo admirado; única condição para avançar.

Revista Plural Você pensa que a sociologia da cultura ainda pode servir de matriz para uma teoria crítica do mundo social? Uma sociologia crítica ainda é possível hoje?

Bernard Lahire Eu diria, de maneira bastante radical, que não conheço sociologia que não seja crítica. Em minha opinião, toda sociologia, quando visa a nos ensinar sobre o funcionamento do mundo social, é potencialmente crítica, no sentido de que revela coisas que não sabíamos, que não podíamos ver (e às vezes nem mesmo queríamos ver) e que às vezes temos dificuldades de "aceitar". Do mesmo modo que foi necessário que as pessoas admitissem que a Terra não era plana, foi preciso que aceitassem as evidências da desigualdade social perante a escola e a cultura que as pesquisas estatísticas colocaram em evidência. Romper com o senso comum (ordinário ou oficial), suspeitar das ilusões, das ideologias deformadoras, das representações espontâneas (e interessadas) é o mínimo que se pode fa- 
zer, parece-me, a partir do momento em que se pretende ser um pesquisador em ciências sociais. Para mim, a sociologia da educação e a sociologia da cultura não são particularmente mais críticas que alguma outra, apesar de, historicamente, os sociólogos críticos nos quais pensamos (Bourdieu, Passeron, etc.) terem começado suas carreiras como sociólogos da educação e da cultura. Eu penso, simplesmente, que hoje a sociologia da cultura, como sociologia das crenças culturais e das categorias de percepção e de apreciação, pode continuar a ser o lugar de uma renovação da sociologia. 
